\title{
Life Goes On - Death and Dying in the Medical Field
}

Sara Hussain.

\section{The Experience}

There is a fine line between empathy and sympathy, caring and worrying. Therein lies the difference between a loved one and a doctor.

Empathy, in its simplest definition, is described as understanding the experiences and difficulties of a second person, while sympathy can be characterized as the heightened awareness of a person's plight and it is needing to be alleviated. ' This concept becomes especially relevant when discussing the importance of empathy in the healthcare environment, where healthcare providers who were deemed to be sympathetic were found to order more investigations and perform cardiopulmonary resuscitation for longer periods than their empathetic counterparts. ${ }^{2}$

If you were to feel every time your patient hurt as your own physical pain, you would not be able to adequately help them, while simultaneously drowning in distress and emotional turmoil. To combat this, the idea of "compassionate detachment" has been advocated, wherein a level of emotional distance is encouraged in the patient doctor relationship. This phrase envelops the idea of empathy without excessive sympathy to maintain a reasonable "affective distance", which would allow the caregiver to make unbiased clinical judgments free from objectivity. ${ }^{3}$ As a doctor, establishing a relationship with your patient built on trust, mutual respect and understanding is vital in reaching that ultimate goal of patient satisfaction.

But in this void, how close do we walk the line? As a caregiver, what is the right balance between protecting yourself and your feelings, and your patient's rights? An image circulated on social media a few years ago of a doctor breaking down over the death of a young teenager they could not resuscitate. While life and death go hand in hand in a hospital; as a student in the preclinical environment, we are just described the idea of death as an arbitrary fact, a consequence of actions and a final stage of life.

I first began exploring this during my attachment in the clinical field. Being naturally drawn to the excitement behind the ER door, I would spend all my free time there talking to patients, watching procedures, or simply walking the corridors. Here I saw my first suture, my first dislocation and first resuscitation. Here, I had my first brush with death.

Towards the end of my first year in a clinical attachment, I became more drawn towards the resuscitation area of the ER, either shadowing a doctor, or as a silent observer, or simply going through documentations and checking file reports. My mentor once told me that the first case you see from any illness or condition tends to be cemented in your mind and you will forever remember even its seemingly inconsequential details. This ideology seemed to hold true during most of my medical training, especially with regards to the first patient I saw after a failed resuscitation. After finishing my afternoon classes one day, I entered the polytrauma section of the resuscitation area and was pleasantly surprised at the serene calmness that was so different from the adrenaline packed energy usually clouding the atmosphere. Almost all the cubicles were empty and seemed to be frozen in time and place, seemingly on standby for the next major crisis. There is always something unsettling about a room that appears to be empty but on closer inspection hums powerfully with memories and withheld potential - waiting patiently to be used again. Opening the door to the final room, I saw a middle-aged lady lying comfortably on her back and gazing serenely at the wall clock by her bed. The complete silence of the room absent of even the most basic hospital machinery did not register to me until later. While in the room, I approached her side, gently introducing myself to not startle her. While I was waiting for a response however, a nurse donning a plastic apron entered the room and gently ushered me away while tying a face mask. A few minutes later a body bag left the room.

As a medical student you get exposed to the idea of death and cadavers early on, both by practical sessions and theoretical. But seeing a person die or seeing them soon after death makes you fully grasp the finality of it all. Knowing that you are the only thing that is standing between your patient and the grave places a heavy burden on the caregiver. Yet as doctors, we cannot save everyone and not everyone wants to be saved; but the pain of a death of a patient never really leaves you; that heartbreak of a life lost, the dejection and melancholy of self-guilt might be easier for some to carry than others.

I do believe that these little doses of grief and emotion are a necessity to a medical professional. It is a harsh reminder of responsibilities, prevention, and vigilance; but it is also a gentle suggestion to remember that both the patient and the doctor are humans. Humans with limitations and mistakes, passion and feelings, all struggling to walk the balance between life and death.

\footnotetext{
1 Rashid Hospital, Dubai Health Authority, Dubai, United Arab Emirates.
} 


\section{Experience}

\section{References}

1. Wispé L. The distinction between sympathy and empathy: To call forth a concept, a word is needed. J Pers Soc Psychol. 1986;50(2):314-321

2. Nightingale SD, Yarnold PR, Greenberg MS. Sympathy, empathy, and physician resource utilization. J Cen Intern Med. 1991 Sep-0ct;6(5):420-3.
3. Hojat M, Connella JS, Nasca TJ, Mangione S, Vergare M. Physician empathy: definition, components, measurement, and relationship to gender and specialty. Am J Psychiatry. 2002 Sep;159(9):1563-9.

\section{Acknowledgments}

None

\section{Conflict of Interest Statement ct Funding}

The Authors have no funding, financial relationships or conflicts of interest to disclose.

Author Contributions

Write the manuscript: SH

Cite as:

Hussain S. Life Goes On - Death and Dying in the Medical Field. Int J Med Students. 2017 Sep-Dec;5(3):115-116 